\title{
Methacholine-induced volume dependence of respiratory resistance in preschool children
}

\author{
F. Marchal, N. Loos, P. Monin, R. Peslin
}

Methacholine-induced volume dependence of respiratory resistance in preschool children. F. Marchal, N. Loos, P. Monin, R. Peslin. (C)ERS Journals Ltd 1999.

ABSTRACT: Enhanced negative volume dependence of airway resistance is associated with bronchoconstriction in tracheostomized paralysed open-chest animals. Significant upper airways responses may be associated with bronchoconstriction and could thereby alter the pattern of volume dependence in spontaneously breathing subjects. The aim of the study was to test whether volume dependence of respiratory resistance $(R r s)$ could be demonstrated in preschool children undergoing routine methacholine challenge.

The volume dependence of respiratory oscillation resistance at 12 and $20 \mathrm{~Hz}(R \mathrm{rs}, 12$ and $R$ rs,20) was examined in eight 4-5.5-yr-old children showing a positive response to methacholine. Multiple linear regression analysis was also used to account for flow dependence during tidal breathing $\left(R r s, 12\right.$ or $\left.R r s, 20=K 1+K 2\left|V^{\prime}\right|+K 3 V\right)$.

$R$ rs,12 and $R$ rs,20 yielded similar results. Negative volume dependence was present at baseline and significantly enhanced by methacholine $(p<0.01)$. For instance, the mean \pm SD inspiratory $K 3$ at $20 \mathrm{~Hz}$ was $-4.1 \pm 1.3 \mathrm{hPa} \cdot \mathrm{s} \cdot \mathrm{L}^{-2}$ at baseline and $-15.0 \pm 4.3 \mathrm{hPa} \cdot \mathrm{s} \cdot \mathrm{L}^{-2}$ after methacholine, in which case it was also larger on expiration than on inspiration $(\mathbf{p}<\mathbf{0 . 0 5})$, possibly as a result of upper airway responses.

A significant increase in the negative volume dependence of respiratory resistance may thus be shown in preschool children in response to methacholine. The volume dependence (K3) during inspiration may be particularly useful in detecting bronchoconstriction, because it is less likely to be affected by upper airway mechanisms than during expiration.

Eur Respir J 1999; 14: 1167-1174.

Laboratoire d'Explorations Fonctionnelles Pédiatriques, Service de Médecine Infantile 1, Hôpital d'Enfants, Unité 14 INSERM de Physiopathologie Respiratoire, Vandoeuvre lès Nancy, France.

Correspondence: F. Marchal

Laboratoire de Physiologie

Faculté de Médecine

9 avenue de la Forêt de Haye, BP 184

F 54505 Vandoeuvre lès Nancy

Cedex

France

Fax: 33383592726

Keywords: Bronchial hyperresponsiveness bronchoconstriction

childhood asthma

respiratory mechanics

respiratory reactance

Received: March 311999

Accepted after revision August 151999

Supported, in part, by Grant JE 2164-UHP Nancy I.

Bronchial hyperresponsiveness is frequently evaluated in preschool children with recurrent cough episodes in order to assess whether a diagnosis of asthma should be made. The usual lack of cooperation with forced expiratory manoeuvres at this age precludes measurement of forced expiratory volume in one second (FEV1). Respiratory resistance (Rrs) is an alternative and may be measured noninvasively during tidal breathing. In routine lung function studies, significant variations in Rrs after pharmacological challenge are taken as evidence of bronchoconstriction. However, several reports indicate that contraction of the upper airways may be asssociated with the bronchoconstriction evoked by histamine or methacholine (Mch) stimulation in adult animals and humans [1-7] and may contribute to the measured increase in resistance.

Data on the respective contributions of upper and lower airways responses to Mch are scarce in the preschool child, although the information may be even more relevant to $R$ rs than to FEV1 measurement. Indeed, upper airway constriction is likely to be more apparent during tidal breathing than during voluntary forced expiration, a co-ordinated motor activity that includes dilation of the glottis [8]. Furthermore, maximum expiratory flow is independent of the extrathoracic airways. Data obtained in tracheostomized and paralysed animals show that the bronchoconstriction resulting from airway challenge is associated with complex alterations in lung mechanics [9-12]. Some of the changes are reflected in the negative volume dependence of airway resistance (Raw), i.e. an increase in $R$ aw with decreasing volume of the lung $[10,13]$. There is hardly any evidence that the volume dependence of $R$ aw induced under such experimental conditions may also be detected in spontaneously breathing young children undergoing Mch inhalation tests.

The forced oscillation technique, using a single sinusoidal pressure signal, provides a number of $R$ rs values, which may be used to describe within-breath variations in $R \mathrm{rs}$, provided the excitation frequency is high enough relative to the respiratory frequency to ensure adequate temporal resolution. Multiple linear regression analysis of $R \mathrm{rs}$ against tidal flow and volume represents an elegant method of estimating the change in Rrs with lung volume while also taking into account its expected flow dependence. Algorithms based on this approach have been described and validated in normal adult subjects $($ e.g. $[14,15])$. This type of analysis has already been applied to other fields of paediatric respiratory mechanics, for instance in studying the relationship between transrespiratory pressure, flow and volume in children undergoing artificial ventilation [16].

The aim of the present study was to describe the pattern of within-breath variations in $R$ rs in preschool children exhibiting a positive response to Mch aerosol challenge with special attention to volume dependence. 


\section{Materials and methods}

\section{Subjects}

Eight children (two males and six females) aged 4-5.5 yrs referred for lung function measurements were included in this study. Seven had a history of chronic cough and one of recurrent upper respiratory tract infections. All had been free of respiratory infection for $\geq 4$ weeks prior to the study. None received bronchodilators or inhaled steroids at the time of the study. All subjects had a normal baseline Rrs at $12 \mathrm{~Hz}(R \mathrm{rs}, 12)$. Normal values for input respiratory impedance had previously been determined during a collaborative study performed in 127 healthy children aged 2.8-7.4 yrs recruited from kindergartens and schools in Rabka, Poland, using equipment similar to that described here. The prediction equation for $R \mathrm{rs}, 12$ (in $\mathrm{hPa} . \mathrm{s} \cdot \mathrm{L}^{-1}$ ) based on height (in $\mathrm{m}$ ) is: in $(R \mathrm{rs}, 12)=2.4914-2.4425 \ln$ height and the SD for $\ln R$ rs is 0.2052 .

The subjects included in this study were selected on the basis of a positive airway response to Mch challenge. The criteria were based on an increase in $R \mathrm{rs}, 12$ of $\geq 50 \%$ associated with a statistically significant decrease in reactance at that frequency. The characteristics of the children are presented in table 1 . The study was approved by the regional committee for human subject experimentation.

\section{Respiratory impedance measurement}

The apparatus for measuring respiratory impedance (Pulmosfor; SEFAM, Vandoeuvre les Nancy, France) was in conformity with the recommendations of the European Working Group on Forced Oscillations [17]. This system has been described in detail previously except for slight modifications in the software for more convenient use and improved handling of data.

Briefly, input pressure was delivered by a loudspeaker around the subject's head enclosed in a canopy. Pressure difference and hence flow across the upper airway wall were thus significantly reduced. The child wore a noseclip and breathed through a mouthpiece connected to a Fleisch no 1 pneumotachograph (Metabo, Hepalinges, Switzerland) attached to a differential pressure transducer (Micro 176PC14HD2 Honeywell $\pm 35 \mathrm{hPa}$, Scarborough, Canada). The input pressure was measured with an identical transducer, matched to the first within $1 \%$ of amplitude and $2^{\circ}$ of phase up to $32 \mathrm{~Hz}$. The common mode rejection ratio of the flow channel was $60 \mathrm{~dB}$ at that frequency. Sinusoidal pressure signals at 12 and $20 \mathrm{~Hz}$ were applied successively for $10-20 \mathrm{~s}$.

\section{Protocol}

Two series of control measurements of respiratory impedance $(Z \mathrm{rs})$ were obtained $\sim 30 \mathrm{~min}$ apart. Each series consisted of at least two periods of acquisition at each frequency. Repeated measurements were also obtained after Mch.

Mch chloride (Laboratoire Allerbio, Varennes-en-Argonne, France) was administered using a De Vilbiss nebulizer (model 5610D; Health Care Worldwide, Somerset, PA, USA) and a dosimeter (Mediprom FDC 88; Mediprom, Paris, France) at the following cumulative doses: 50, $100,200,400,800$ and $1200 \mu \mathrm{g}$. When Rrs,12 had increased by $\geq 50 \%$, the next dose was given and the test stopped thereafter. The Mch dose with the largest Rrs,12 was analysed as the maximum response. Reversibility was obtained at the end of the test by inhalation of 2 puffs of Bronchodual $\mathbb{R}$ a mixture of fenoterol bromhydrate (50 $\left.\mu \mathrm{g} \cdot \mathrm{dose}^{-1}\right)$ and ipratropium bromide $\left(20 \mu \mathrm{g} \cdot \mathrm{dose}^{-1}\right)$ delivered through an inhalation chamber.

\section{Respiratory impedance processing and data analysis}

Pressure and flow signals were low-pass filtered at 32 $\mathrm{Hz}$ using analogue filters and digitized at a sampling rate of $320 \mathrm{~Hz}$. The signals were analysed oscillation cycle by oscillation cycle, providing 12 or $20 \mathrm{Zrs}$ measurements per second, depending on the excitation frequency. The breathing component of the signals was eliminated using a digital high-pass filter with a corner frequency of respectively 6 and $10 \mathrm{~Hz}$. The Fourier coefficients of pressure and flow at the excitation frequency were computed and combined to obtain $R \mathrm{rs}$ and respiratory reactance $(X \mathrm{rs})$ according to the usual equations [18]. The data were corrected for the 2.1 ms time constant of the pneumotachograph. Each dataset was then filtered to eliminate aberrant $Z$ rs values, usually associated with rapid-flow transients. The filtering procedure consisted of eliminating those points lying outside the $99 \%$ confidence interval, i.e. lower or higher than the mean \pm 3 SD and was repeated three times.

Table 1. - Anthropometric and lung function data of infants studied

\begin{tabular}{lcccccrrrr}
\hline $\begin{array}{l}\text { Subject } \\
\text { No. }\end{array}$ & Diagnosis & Sex & $\begin{array}{c}\text { Age } \\
\text { yrs }\end{array}$ & $\begin{array}{c}\text { Height } \\
\mathrm{cm}\end{array}$ & $\begin{array}{c}\text { Weight } \\
\mathrm{kg}\end{array}$ & $\begin{array}{c}R \mathrm{rs}, 12 \\
\mathrm{hPa} \cdot \mathrm{s} \cdot \mathrm{L}^{-1}\end{array}$ & $\begin{array}{c}\mathrm{CV} \\
\%\end{array}$ & $\begin{array}{c}R \mathrm{rs}, 12 \\
\% \mathrm{pred}\end{array}$ & $\begin{array}{c}\text { PD50 } \\
\mu \mathrm{g}\end{array}$ \\
\hline 1 & URTI & $\mathrm{F}$ & 4.0 & 108.0 & 20.0 & 12.3 & 11.3 & 122 & 50 \\
2 & Cough & $\mathrm{M}$ & 4.0 & 103.0 & 17.0 & 12.7 & 11.9 & 113 & 470 \\
3 & Cough & $\mathrm{F}$ & 4.7 & 108.0 & 20.0 & 12.2 & 4.7 & 122 & 280 \\
4 & Cough & $\mathrm{M}$ & 4.0 & 101.0 & 15.0 & 12.8 & 11.1 & 109 & 700 \\
5 & Cough & $\mathrm{F}$ & 4.0 & 108.0 & 18.0 & 8.3 & 5.5 & 83 & 68 \\
6 & Cough & $\mathrm{F}$ & 4.0 & 110.0 & 19.0 & 11.3 & 10.3 & 118 & 160 \\
7 & Cough & $\mathrm{F}$ & 5.5 & 122.0 & 22.0 & 8.3 & 14.2 & 112 & 500 \\
8 & Cough & $\mathrm{F}$ & 4.5 & 111.0 & 23.0 & 8.9 & 9.1 & 95 & 450 \\
Mean & & & 4.3 & 108.9 & 19.3 & 10.9 & 9.8 & 109 & 335 \\
SD & & & 0.5 & 6.3 & 2.6 & 1.9 & 3.2 & 14 & 233 \\
\hline
\end{tabular}

$R \mathrm{rs}, 12$ : respiratory resistance at $12 \mathrm{~Hz}$; CV: coefficient of variation (of $R \mathrm{rs}, 12$ ); PD50: methacholine dose provoking a $50 \%$ increase in Rrs,12; URTI: upper respiratory tract infection; F: female; M: male. 
The time courses of tidal flow and volume, $R$ rs and $X$ rs were then displayed on the computer screen and the overall $R \mathrm{rs}$ mean for the acquisition epoch obtained.

The data were stored on disk for off-line multiple linear regression analysis in order to describe the within-breath variations in Rrs separately for inspiration and expiration and assuming linear flow and volume dependence. The following equations were used:

$$
\begin{aligned}
& R_{\mathrm{rs}, \mathrm{I}}=K 1+K 2\left|V^{\prime}\right|+K 3 V \\
& R_{\mathrm{rs}, \mathrm{E}}=K 1+K 2\left|V^{\prime}\right|+K 3 V
\end{aligned}
$$

where $R \mathrm{rs}, \mathrm{I}$ and $R \mathrm{rs}, \mathrm{E}$ are $R \mathrm{rs}$ during inspiration and expiration respectively $V^{\prime}$ and $V$ are the flow and volume means during the corresponding oscillation cycle, $K 1$ is the resistance at functional residual capacity (FRC) and zero flow, and $K_{2}$ and $K 3$ account for the flow and volume dependence of $R$ rs respectively. The statistical significance of the multiple linear regression coefficients was assessed from their corresponding $\mathrm{F}$ ratio. Only those coefficients with $F$ ratios significant at $p<0.05$ were retained. Data were compared using a paired t-test and expressed as mean $\pm \mathrm{SD}$ unless otherwise indicated.

\section{Results}

\section{Baseline}

Representative trace of flow, $R \mathrm{rs}, 12$ and $R \mathrm{rs}$ at $20 \mathrm{~Hz}$ $(R \mathrm{rs}, 20)$ at baseline are displayed in figure 1. Large fluctuations in $R \mathrm{rs}, 12$ and $R \mathrm{rs}, 20$ may be seen and the resistance was minimal at zero flow. The flow dependence of $R \mathrm{rs}, 20$ is depicted in figure $2 \mathrm{a}$, in which there appears to be a slight hysteresis during expiration. In this example, the values of $K_{2}$ during inspiration and expiration (K2I and $K 2 \mathrm{E}$ ), as determined from equations 1 and 2 , are res-

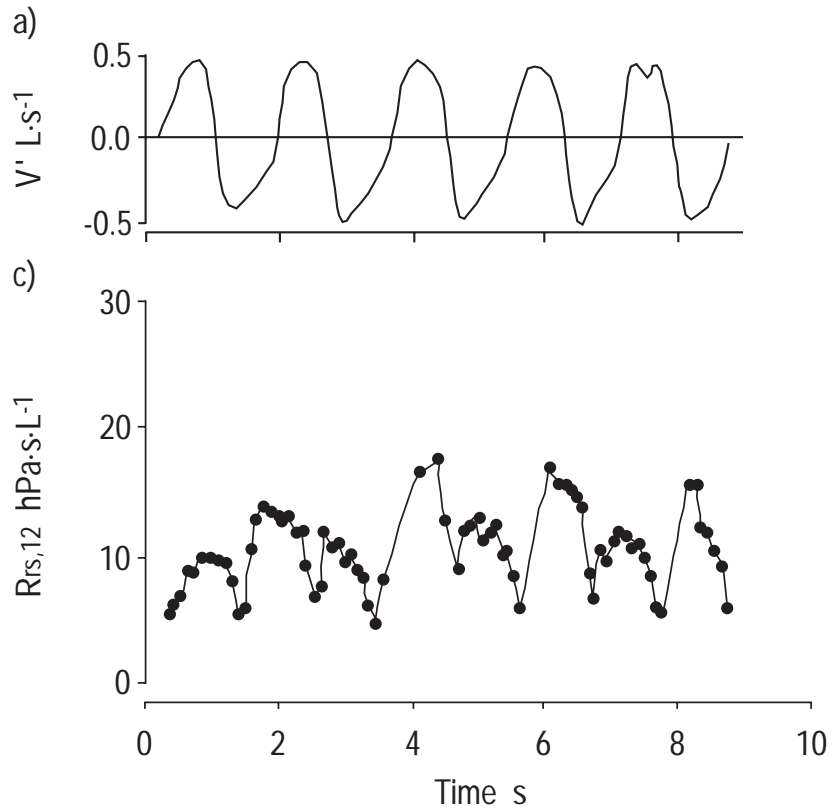

pectively 18.1 and $27.3 \mathrm{hPa} \cdot \mathrm{s}^{2} \cdot \mathrm{L}^{-2}$. Corresponding values at $12 \mathrm{~Hz}$ are respectively 13.8 and $26.7 \mathrm{hPa} \cdot \mathrm{s}^{2} \cdot \mathrm{L}^{-2}$. The "zero flow" Rrs,20, i.e. Rrs,20 - K2 $\left|V^{\prime}\right|$ plotted against tidal volume in figure $2 \mathrm{~b}$, shows slight negative volume dependence on expiration but not on inspiration.

The mean baseline data at 12 and $20 \mathrm{~Hz}$ are summarized respectively in tables 2 and 3 . R Rrs at both frequencies showed flow dependence with significant $K 2$ in all children $R$ rs, 12 was significantly greater during expiration than during inspiration. The difference appeared to be related to the nonlinear component of the resistance since $K 2$ but not $K 1$ was larger during expiration than during inspiration. A similar difference in $K 2$ was observed at 20 Hz. $K 3$ was less systematically significant, particularly during inspiration, during which only six of eight subjects showed significant values, which were usually negative. $K 3$ during expiration $(K 3 \mathrm{E})$ tended to be more negative than $K 3$ during inspiration $(K 3 \mathrm{I})$ at both frequencies, but the difference did not reach statistical significance $(\mathrm{p}=$ 0.08 at $12 \mathrm{~Hz}$ and 0.06 at $20 \mathrm{~Hz}$ ).

\section{Methacholine}

At maximum response to Mch. Rrs, 12 and $R$ rs, 20 were markedly increased and the periodic variations were not strictly in phase with flow (fig. 3). This was more easily detected with $R$ rs, 20 than $R \mathrm{rs}, 12$, because of better time resolution. The Rrs,20/flow diagram shows marked hysteresis (fig. 4a). This expresses striking volume dependence, occurring during both expiration and inspiration (fig. 4b). Similar findings were observed for $R \mathrm{rs}, 12$.

A representative dose/response curve for $R$ rs and $K 3$ at 12 and $20 \mathrm{~Hz}$ is shown in figure 5 . There was an increasingly negative $K 3$ with cumulative Mch dose, together with an increase in Rrs. The variability appears to increase after Mch, in relation to the mean amplitude of

b)

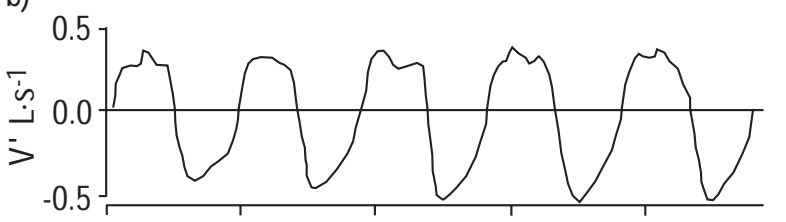

d)

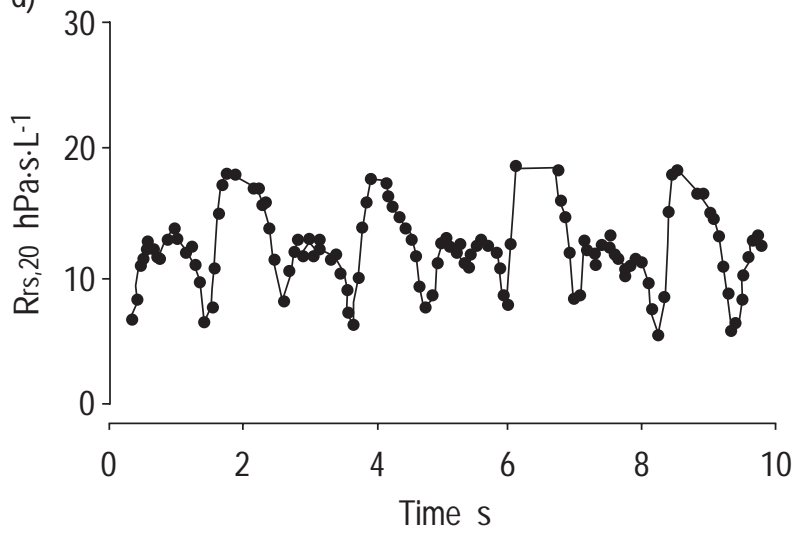

Fig. 1. - Representative time courses of: a, b) tidal flow $\left(V^{\prime}\right)$ and c, d) respiratory resistance $(R \mathrm{rs})$ at $12(R \mathrm{rs}, 12)$ and $20 \mathrm{~Hz}(R \mathrm{rs}, 20)$ at baseline. Flow values are negative during expiration. Both $R \mathrm{rs}, 12$ and $R \mathrm{rs}, 20$ show periodic within-breath fluctuations. Most of the $R \mathrm{rs}$ variation is reflected in the absolute value of the tidal flow. 

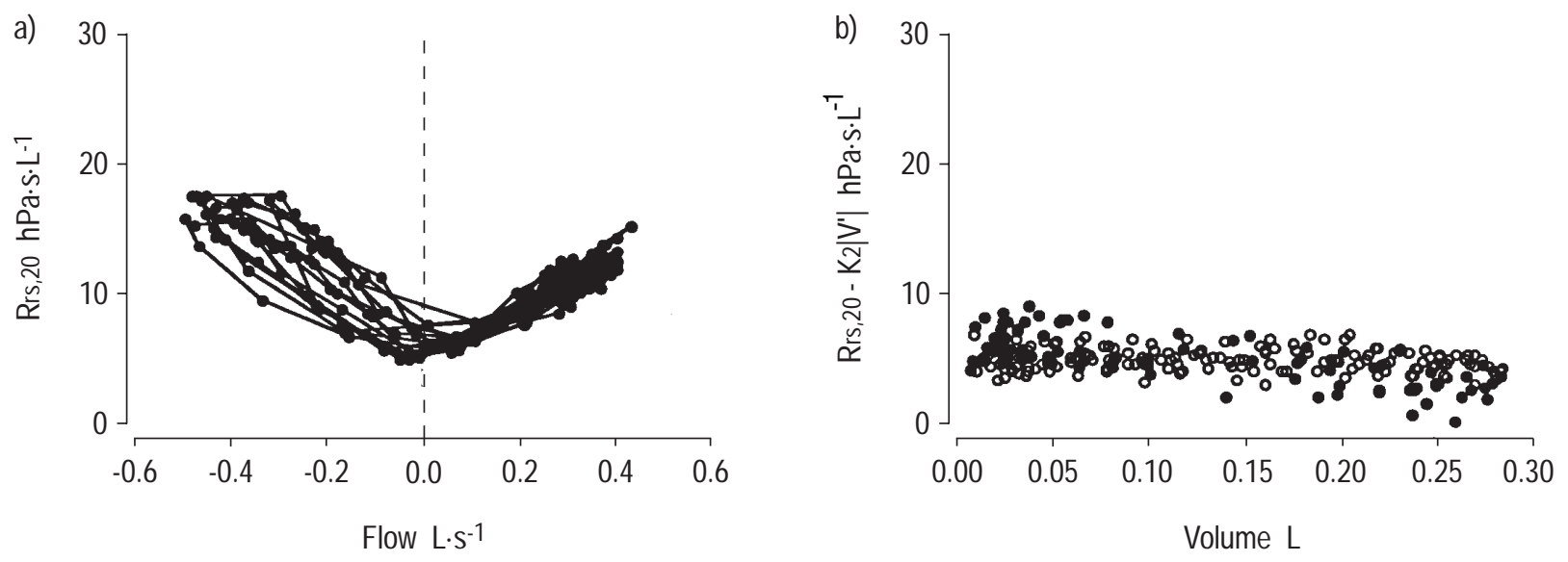

Fig. 2. - Plot of: a) respiratory resistance at $20 \mathrm{~Hz}(R \mathrm{rs}, 20)$ against tidal flow; and b) flow-corrected $R \mathrm{rs}, 20\left(R \mathrm{rs}, 20-K 2\left|V^{\prime}\right|\right)$ against volume at baseline, during inspiration $(\bigcirc)$ and expiration $(\bullet)$. Note the obvious flow dependence of $R \mathrm{rs}, 20$ (a). Some degreee of negative volume dependence during expiration is suggested by the slight hysteresis of the $R \mathrm{rs}, 20 /$ flow relationship (a) and indicated by the negative slope of the flow-corrected $R \mathrm{rs}, 20 \mathrm{volume}$ relationship (b).

corresponding parameter. The population mean coefficients of variation for $K 3 \mathrm{I}$ and $K 3 \mathrm{E}$ after Mch were 26.9 and $23.5 \%$ at $12 \mathrm{~Hz}$ and 24.6 and $25.1 \%$ at $20 \mathrm{~Hz}$ respectively.

The mean Mch data at maximum response are given in tables 2 and 3 at each frequency. All coefficients of flow or volume dependence were significant. Furthermore, all values were significantly different from baseline, so that $R \mathrm{rs}, 12$ and $R \mathrm{rs}, 20$ not only were greater than control values but also more flow- and volume-dependent. There was also more flow-dependence during expiration than inspiration, as already found at baseline. $K 3$ was also larger during expiration than inspiration at both frequencies. There was no significant difference between 12 and $20 \mathrm{~Hz}$ for any parameter.

Finally, the percentage change in $R$ rs and change in $K 3$ were computed for the last five Mch doses, as shown in figure 6. A decrease in $K 3$ was consistently associated with the increase in $R$ rs. The decrease in $K 3$ appeared larger on expiration than on inspiration at the last two doses, the difference being statistically significant for the data at $12 \mathrm{~Hz}$.

\section{Discussion}

This study demonstrates that preschool children exhibit significant tidal flow and volume related variations in $R \mathrm{rs}$ that may differ during inspiration and expiration and be markedly altered by aerosol Mch.
The subjects were selected according to the magnitude of their $R \mathrm{rs}, 12$ response and the significant decrease in $X_{\mathrm{rs}}$ at $12 \mathrm{~Hz}(\mathrm{Xrs}, 12)$ at the corresponding Mch dose. It has, indeed been, previously reported that the Mch-induced decrease in $X \mathrm{rs}, 12$ calculated from $Z$ rs measurements using a head generator significantly correlated to the percentage change in FEV1 [19]. A head generator was used because it minimizes upper airway wall motion $[20,21]$ and has been shown to improve the estimation of $\mathrm{Zrs}$ in children with airway obstruction [22] as well as the sensitivity of the forced oscillation technique in describing withinbreath variations in $R$ rs in adult subjects [23]. When discussing the physiological implications of the changes in $R \mathrm{rs}$, it is important to bear in mind that the coefficients defined in equations 1 and 2 describe a temporal association with flow or volume which does not necessarily imply causality. This may be of particular importance in understanding the contribution of the upper airways.

$R$ rs showed significant flow dependence and Mch was associated with an increase in $K 1$ and $K 2$, which are both determined by Reynolds number [24]. The latter increases with induced airway obstruction, and turbulent flow extends to parts of the airways in which it was previously laminar [25]. Thus, although a coefficient accounting for flow dependence must be included to properly describe the within-breath variations in $R \mathrm{rs}$, changes in $K 1$ or $K 2$ do not help to locate the response within the airways. Accordingly, the $K 2: K 1$ ratios appeared similar at baseline and after Mch.

Table 2. - Respiratory resistance at $12 \mathrm{~Hz}(R \mathrm{rs}, 12)$ and derived coefficients of flow and volume dependence

\begin{tabular}{llcccccccc}
\hline & $\begin{array}{c}R \mathrm{rs}, 12, \mathrm{I} \\
\mathrm{hPa} \cdot \mathrm{s} \cdot \mathrm{L}^{-1}\end{array}$ & $\begin{array}{c}R \mathrm{rs}, 12, \mathrm{E} \\
\mathrm{hPa} \cdot \mathrm{s} \cdot \mathrm{L}^{-1}\end{array}$ & $\begin{array}{c}K 1 \mathrm{I} \\
\mathrm{hPa} \cdot \mathrm{s} \cdot \mathrm{L}^{-1}\end{array}$ & $\begin{array}{c}K 1 \mathrm{E} \\
\mathrm{hPa} \cdot \mathrm{s} \cdot \mathrm{L}^{-1}\end{array}$ & $\begin{array}{c}K 2 \mathrm{I} \\
\mathrm{hPa} \cdot \mathrm{s}^{2} \cdot \mathrm{L}^{-2}\end{array}$ & $\begin{array}{c}K 2 \mathrm{E} \\
\mathrm{hPa} \cdot \mathrm{s}^{2} \cdot \mathrm{L}^{-2}\end{array}$ & $\begin{array}{c}K 3 \mathrm{I} \\
\mathrm{hPa} \cdot \mathrm{s} \cdot \mathrm{L}^{-2}\end{array}$ & $\begin{array}{c}K 3 \mathrm{E} \\
\mathrm{hPa} \cdot \mathrm{s} \cdot \mathrm{L}^{-2}\end{array}$ \\
\hline Baseline & Mean & 10.3 & $11.4^{+}$ & 6.7 & 6.9 & 12.4 & $20.5^{+}$ & -6.8 & -10.5 \\
& $\mathrm{SD}$ & 1.5 & 2.5 & 0.6 & 0.8 & 3.3 & 7.3 & 1.9 & 6.0 \\
\multirow{5}{*}{ Methacholine } & $\mathrm{n}$ & 8 & 8 & 8 & 8 & 8 & 8 & 6 & 7 \\
& Mean & $17.6^{*}$ & $18.7^{*}$ & $11.4^{*}$ & $11.6^{*}$ & $23.9^{*}$ & $34.4^{*},+$ & $-16.0^{*}$ & $-30.1^{*,+}$ \\
& $\mathrm{SD}$ & 1.4 & 1.7 & 2.4 & 3.2 & 6.0 & 5.7 & 2.7 & 18.6 \\
& $\mathrm{n}$ & 8 & 8 & 8 & 8 & 8 & 8 & 8 & 8 \\
\hline
\end{tabular}

Rrs,12,I: $R$ rs,12 during inspiration; $R \mathrm{rs}, 12, \mathrm{E}: R \mathrm{rs}, 12$ during expiration; $K 1 \mathrm{I}$ and $K 1 \mathrm{E}: R \mathrm{rs}, 12$ at zero flow and constant volume during inspiration and expiration; $K 2 \mathrm{I}$ and $K 2 \mathrm{E}$ : coefficient of flow dependence of $R \mathrm{rs}, 12$ during inspiration and expiration; K3I and $K 3 \mathrm{E}$ : coefficient of volume dependence of $R \mathrm{rs}, 12$ during inspiration and expiration; n: number of significant coefficients. ${ }^{*}: \mathrm{p}<0.05$ versus baseline; ${ }^{+}: \mathrm{p}<0.05$ versus inspiration. 
Table 3. - Respiratory resistance at $20 \mathrm{~Hz}(R \mathrm{rs}, 20)$ and coefficients of flow and volume dependence

\begin{tabular}{llcccccccc}
\hline & $\begin{array}{c}R \mathrm{rs}, 20, \mathrm{I} \\
\mathrm{hPa} \cdot \mathrm{s} \cdot \mathrm{L}^{-1}\end{array}$ & $\begin{array}{c}R \mathrm{rs}, 20, \mathrm{E} \\
\mathrm{hPa} \cdot \mathrm{s} \cdot \mathrm{L}^{-1}\end{array}$ & $\begin{array}{c}K 1 \mathrm{I} \\
\mathrm{hPa} \cdot \mathrm{s} \cdot \mathrm{L}^{-1}\end{array}$ & $\begin{array}{c}K 1 \mathrm{E} \\
\mathrm{hPa} \cdot \mathrm{s} \cdot \mathrm{L}^{-1}\end{array}$ & $\begin{array}{c}K 2 \mathrm{I} \\
\mathrm{hPa} \cdot \mathrm{s}^{2} \cdot \mathrm{L}^{-2}\end{array}$ & $\begin{array}{c}K 2 \mathrm{E} \\
\mathrm{hPa} \cdot \mathrm{s}^{2} \cdot \mathrm{L}^{-2}\end{array}$ & $\begin{array}{c}K 3 \mathrm{I} \\
\mathrm{hPa} \cdot \mathrm{s} \cdot \mathrm{L}^{-2}\end{array}$ & $\begin{array}{c}K 3 \mathrm{E} \\
\mathrm{hPa} \cdot \mathrm{s} \cdot \mathrm{L}^{-2}\end{array}$ \\
\hline Baseline & Mean & 10.8 & 11.4 & 6.8 & 6.7 & 14.4 & $22.8^{+}$ & -4.1 & -9.6 \\
& $\mathrm{SD}$ & 1.6 & 2.3 & 1.0 & 1.3 & 3.9 & 6.9 & 1.3 & 5.0 \\
Methacholine & $\mathrm{n}$ & 8 & 8 & 8 & 8 & 8 & 8 & 6 & 8 \\
& Mean & $18.2^{*}$ & $19.1^{*}$ & $12.1^{*}$ & $12.0^{*}$ & $24.0^{*}$ & $38.5^{*},+$ & $-15.0^{*}$ & $-28.6^{*}+$, \\
& $\mathrm{SD}$ & 2.0 & 2.5 & 1.7 & 2.4 & 7.1 & 11.1 & 4.3 & 21.2 \\
& $\mathrm{n}$ & 8 & 8 & 8 & 8 & 8 & 8 & 8 & 8 \\
\hline
\end{tabular}

$R \mathrm{rs}, 20, \mathrm{I}: R \mathrm{rs}, 20$ during inspiration; $R \mathrm{rs}, 20, \mathrm{E}: R \mathrm{rs}, 20$ during expiration; $K 1 \mathrm{I}$ and $K 1 \mathrm{E}: R \mathrm{rs}, 20$ at zero flow and constant volume during inspiration and expiration; $K 2 \mathrm{I}$ and $K 2 \mathrm{E}$ : coefficient of flow dependence of $R \mathrm{rs}, 20$ during inspiration and expiration; K3I and $K 3 \mathrm{E}$ : coefficient of volume dependence of $R \mathrm{rs}, 20$ during inspiration and expiration; $\mathrm{n}$ : number of significant coefficients. ${ }^{*}: \mathrm{p}<0.05$ versus baseline; ${ }^{+}: \mathrm{p}<0.05$ versus inspiration.

The experimental evidence in animals is that $R$ rs measured at frequencies $\geq 12 \mathrm{~Hz}$ is little influenced by lung [9, $26]$ and chest wall tissues [26]. Conversely, the chest wall has been estimated to contribute nearly $50 \%$ of the Rrs in adult humans [27] in whom Zrs also showed significant $K 3$ values within the tidal range $[14,15]$. The partitioning of $R$ rs, however, indicated that chest wall tissues did not show consistent volume-related variations [28]. Plethysmographic measurements in normal adults have demonstrated the hyperbolic relationship between Raw and lung volume in the range of the total lung capacity [25]. In infants, plethysmographic studies have shown variation in Raw during the respiratory cycle, alinearities of the pressure/flow relationship [29] and hysteresis of this curve on expiration in the presence of airways obstruction [30]. Recently, volume dependence of Raw estimated from model fitting of input $Z$ rs data was demonstrated in eight infants during an induced apnoea [31]. The significant $K 3$ s observed in the current study are thus likely to be attributed to the airways. This negative volume dependence of $R$ aw, as demonstrated in a variety of ani- mal species ventilated through a tracheostomy (e.g. [9, 13]) may, in a simplified manner, be explained by the increasing stretch on intraparenchymatous airways related to elastic lung recoil, which increases with lung volume [25].

The consistent and large increase in the negative volume dependence of Rrs after Mch is a major finding of the present study. There are a few reports of the volume dependence of $R_{\mathrm{rs}}$ in adult subjects with airways obstruction [3, 32], but the authors are unaware of such analysis in young children. Spontaneous breathing is a condition which does not allow control of variations in end-expiratory lung volume and represents a possible confounding factor. Nevertheless, the present observation is in keeping with studies in paralysed artificially ventilated animals, in which the experimental design allowed relative control of lung volume, the variations in which were imposed by application of graded levels of positive end-expiratory pressure $[10,13]$. The mechanisms involved in explaining the increased negative volume dependence of Rrs after Mch include partial airway closure at
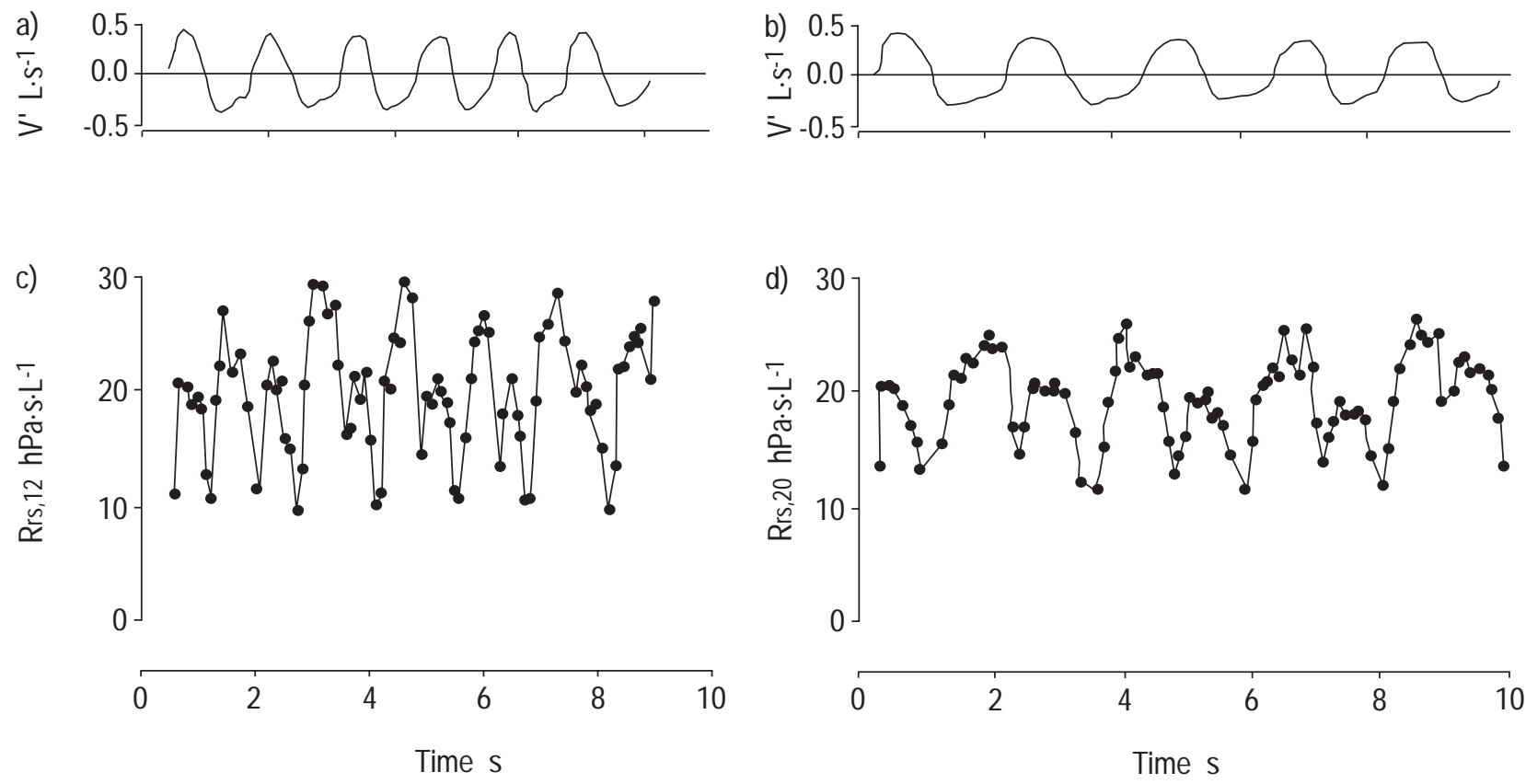

Fig. 3. - Representative time courses of: a, b) tidal flow $\left(V^{\prime}\right)$ and c, d) respiratory resistance $(R \mathrm{rs})$ at $12(R \mathrm{rs}, 12)$ and $20 \mathrm{~Hz}(R \mathrm{rs}, 20)$ at maximum response to methacholine. Note the altered pattern of within-breath variations in $R$ rs at both frequencies. Rrs variations are less strictly in phase with flow, compared with control. The amplitude of the periodic Rrs variation, particularly at $12 \mathrm{~Hz}$ in this example, was also increased, whereas there was little change in flow amplitude compared with baseline. 

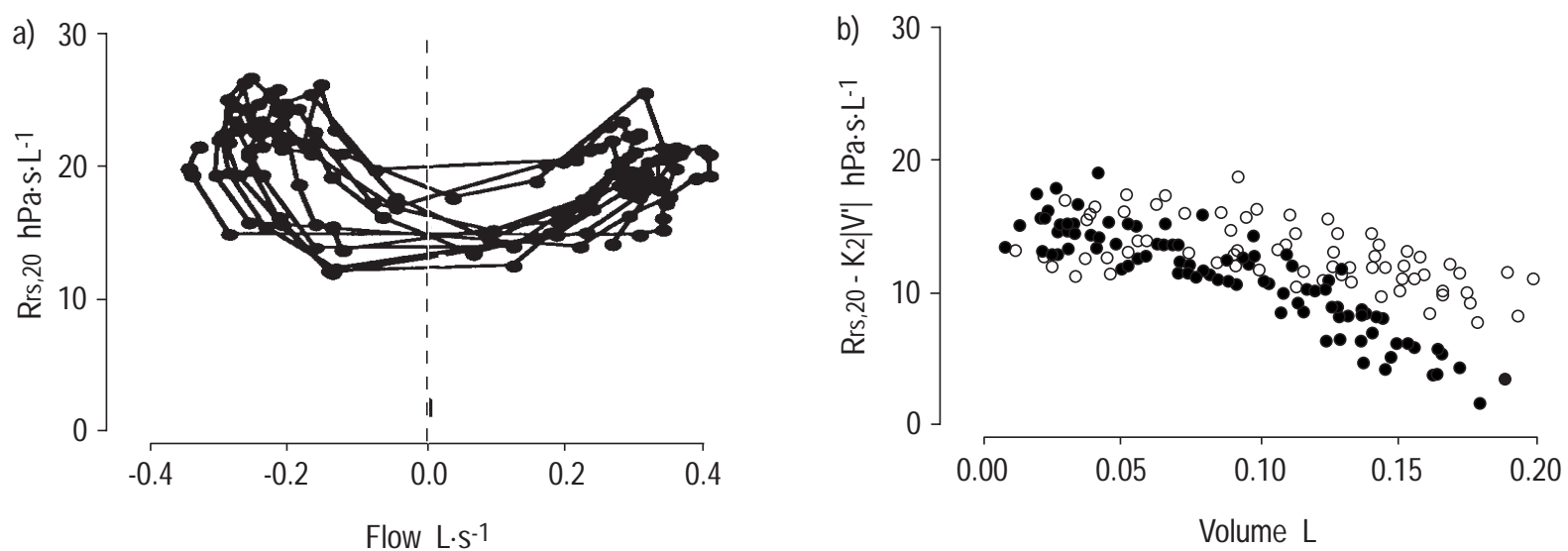

Fig. 4. - Plot of: a) respiratory resistance at $20 \mathrm{~Hz}(R \mathrm{rs}, 20)$ against tidal flow; and b) flow-corrected $R \mathrm{rs}, 20\left(R \mathrm{rs}, 20-K 2\left|V^{\prime}\right|\right)$ against volume at maximum response to methacholine, during inspiration $(O)$ and expiration $(\bullet)$. A marked increased in the volume dependence of $R \mathrm{rs}, 20$ occurs, during both inspiration and expiration and is shown by the hysteresis of the $R \mathrm{rs}, 20 /$ flow relationship (a) and the negative slope of the flow-corrected $R$ rs, 20 /volume relationship (b). Note the difference from the corresponding relationships at baseline in figure 2 .

low lung volume (in the present case near the FRC), increased coupling of airways and parenchyma related to the bronchoconstriction and/or to stiffening of lung tissue $[10,12,33]$. The current study cannot however provide evidence as to the mechanisms involved.

$K 3$ tended to be larger during expiration than inspiration at baseline, and the difference was significant after Mch (tables 2 and 3), indicating that flow-corrected Rrs,I and $R$ rs,E may differ at the same lung volume. This difference may point toward a contribution of the upper airways. Indeed, in normal adults, the glottic diameter has been shown to be smaller during expiration than during inspiration at a given volume and to frequently exhibit progressive narrowing throughout expiration, abrupt widening at the onset of inspiration and little change further throughout this part of the cycle [34]. Adding the effects of the upper airways and the lower respiratory system would then yield a larger apparent volume dependence of total Rrs during expiration than during inspiration. Fibreoptic studies have documented increased glottis narrowing after inhaled or intravenous histamine in normal adults [7] and after inhaled Mch in normal adults [6] and asthmatics [5]. This observation was extended to both the glottis and pharynx of normal subjects challenged with Mch by studying the pattern of acoustic reflections in the

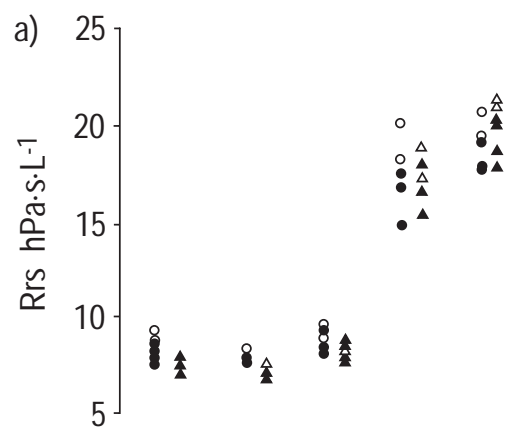

8

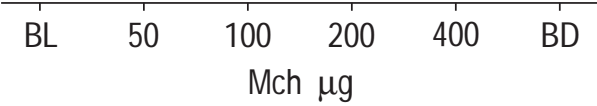

proximal airways [4]. Altogether, the glottis adduction was reported to be more pronounced during expiration than inspiration (e.g. $[5,7])$ which may explain why $K 3 \mathrm{E}$ was more negative than $K 3$ I after Mch (tables 2 and 3). Thus, during both control and Mch measurements, the volume dependence of $R$ rs is less likely to be affected by the upper airways during inspiration than during expiration.

To summarize these findings, in preschool children breathing spontaneously, significant fluctuations in $R$ rs reflect changes in the characteristics of the pressure/flow relationship and in airways calibre throughout the respiratory cycle. Of clinical relevance is the enhanced negative volume dependence of $R$ rs when the airway response to Mch is positive. The mechanisms may involve different levels of the respiratory system. Increased interdependence between intraparenchymatous airways and lung tissues and/ or partial closure of the airways may relate the phenomenon to mechanical alterations of the lung and the intrathoracic airways. Conversely, the pattern of expiratory change in laryngeal dimensions and the reflex laryngeal response that may be associated with the bronchoconstriction may to some degree cause volume dependence of $R$ rs during expiration. Because the inspiratory phase is likely to be free of progressive laryngeal narrowing, $\mathrm{K} 3 \mathrm{I}$ is expected

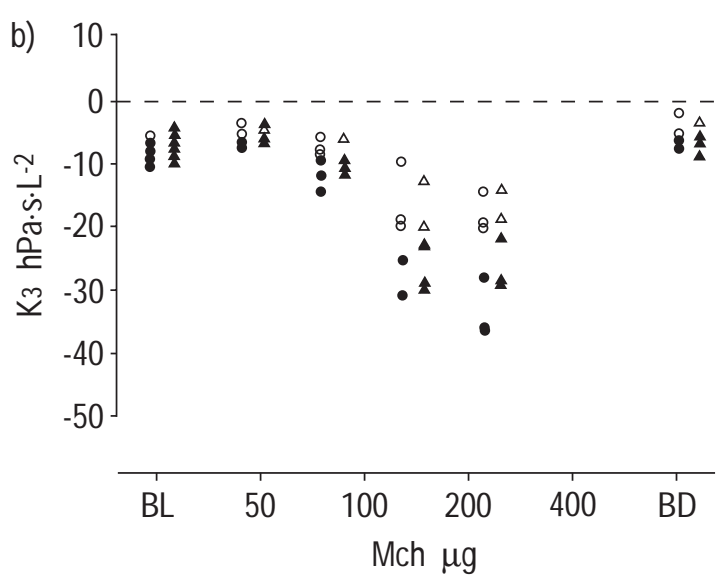

Fig. 5. - Representative methacholine (Mch) dose/response curves for: a) respiratory resistance (Rrs) and b) the coefficient of volume dependence of Rrs $(K 3)$ in one child. The raw data are shown for $12(\bullet, \bigcirc)$ and $20 \mathrm{~Hz}(\mathbf{\Delta}, \triangle)$ during inspiration $(\mathrm{O}, \triangle)$ and expiration $(\bullet, \mathbf{\Delta})$ at baseline $(\mathrm{BL})$ and at different cumulative Mch doses; reversibility by bronchodual (BD) is also shown. 

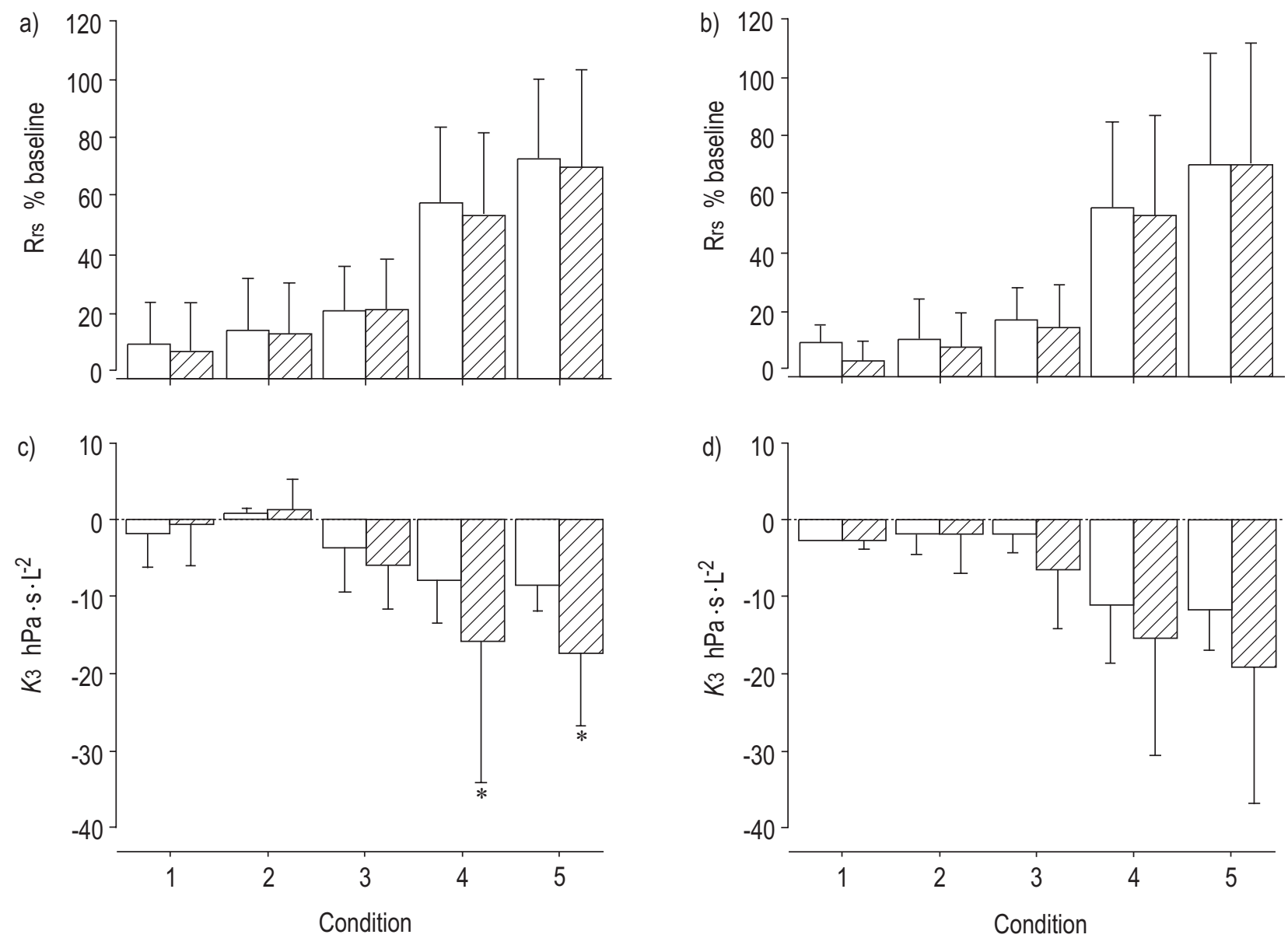

Fig. 6. - Change $(\Delta)$ in: a, b) respiratory resistance $(R \mathrm{rs})$; and b) the coefficient of volume dependance of $R \mathrm{rs}(K 3)$ from baseline in response to methacholine in the study population at: a, c) $12 \mathrm{~Hz}$; and b, d) $20 \mathrm{~Hz}$ during inspiration $(\square)$ and expiration $(\mathbb{Z})$. Data are presented as mean \pm SD and pooled for the maximum response (condition 5) and the four preceding doses (conditions $1-4){ }^{*}: \mathrm{p}<0.05$ versus inspiration.

to more specifically reflect alterations at the level of the intrathoracic airways.

From a practical point of view, it is speculated that the volume dependence of Rrs during inspiration can potentially be used to detect the response of intrathoracic airways during Mch challenge. Further studies are, therefore, needed to establish the correspondence of this parameter with more conventional indices, such as forced expiratory volume in one second, and to assess its practical usefulness in the routine interpretation of airway challenge test results.

\begin{abstract}
Acknowledgements. The authors thank B. Chalon, G. Colin and C. Duvivier for engineering and technical assistance, C. Choné, M.T. Didier, F. Fortin, O. Lacome and S. Méline for lung function measurements, and C. Creusat and N. Bertin for secretarial help.
\end{abstract}

\section{References}

1. Di Maria GU, Wang CG, Bates JHT, Guttmann R, Martin JG. Partitioning of airway responses to inhaled methacholine in the rat. J Appl Physiol 1987; 62: 1317-1323.

2. Jammes Y, Davies A, Widdicombe JG. Tracheobronchial and laryngeal responses to hypercapnia, histamine and capsaicin in dogs. Bull Eur Physiopathol Respir 1985; 21 : $515-520$.
3. Shindoh C, Sekizawa K, Hida W, Sasaki H, Takishima T. Upper airway response during bronchoprovocation and asthma attack. Am Rev Respir Dis 1985; 132: 671678.

4. Brown IG, Zamel N, Hoffstein V. Pharyngeal and glottic changes following methacholine challenge in normal subjects. Bull Eur Physiopathol Respir 1986; 22: 251256.

5. Collett PW, Brancatisano T, Engel LA. Changes in the glottic aperture during bronchial asthma. Am Rev Respir Dis 1983; 128: 719-723.

6. England SJ, Ho V, Zamel N. Laryngeal constriction in normal humans during experimentally induced bronchoconstriction. J Appl Physiol 1985; 58: 352-356.

7. Higenbottam T. Narrowing of glottis opening in humans associated with experimentally induced bronchoconstriction. J Appl Physiol 1980; 49: 403-407.

8. Brancatisano T, Dodd D, Engel LA. Factors influencing glottic dimensions during forced expiration. J Appl Physiol 1983; 55: 1825-1829.

9. Ludwig MS, Dreshaj I, Solway J, Munoz A, Ingram RH. Partitioning of pulmonary resistance during constriction in the dog: effects of volume history. J Appl Physiol 1987; 62: 807-815.

10. Bates JHT, Lauzon AM, Dechman GS, Maksym GN, Schuessler TF. Temporal dynamics of pulmonary response to intravenous histamine in dogs: effects of dose and lung volume. J Appl Physiol 1994; 75: 616-626. 
11. Lutchen KR, Hantos Z, Petak F, Adamicza A, Suki B Airway inhomogeneities contribute to apparent lung tissue mechanics during constriction. J Appl Physiol 1996; 80: $1841-1849$.

12. Nagase T, Moretto A, Ludwig MS. Airway and tissue behavior during induced constriction in rats: intravenous versus aerosol administration. J Appl Physiol 1994; 76: 830-838.

13. Nagase T, Martin JG, Ludwig MS. Comparative study of mechanical interdependence: effect of lung volume on Raw during induced constriction. J Appl Physiol 1993; 75: 2500-2505.

14. Peslin R, Ying Y, Gallina C, Duvivier C. Within-breath variations of forced oscillation resistance in healthy subjects. Eur Respir J 1992; 5: 86-92.

15. Tomalak W, Peslin R, Duvivier C. Variations in airways impedance during respiratory cycle derived from combined measurements of input and transfer impedances. Eur Respir J 1998; 12: 1436-1441.

16. Rousselot JM, Peslin R, Duvivier C. Evaluation of the multiple linear regression method to monitor respiratory mechanics in ventilated neonates and young children. Pediatr Pulmonol 1992; 13: 161-168.

17. Van de Woestijne KP, Desager KN, Duiverman EJ, Marchal F. Recommendations for measurement of respiratory input impedance by means of the forced oscillation method. Eur Respir Rev 1994; 4: 235-237.

18. Michaelson ED, Grassman ED, Peters WR. Pulmonary mechanics by spectral analysis of forced random noise. $J$ Clin Invest 1975; 56: 1210-1230.

19. Bouaziz N, Beyaert C, Gauthier R, Monin P, Peslin R, Marchal F. Respiratory system reactance as an indicator of the intrathoracic airway response to methacholine in children. Pediatr Pulmonol 1996; 22: 7-13.

20. Cauberghs M, Van de Woestijne KP. Effect of upper airway shunt and series properties on respiratory impedance measurements. J Appl Physiol 1989; 66: 2274-2279.

21. Peslin R, Duvivier C, Didelon J, Gallina C. Respiratory impedance measured with head generator to minimize upper airway shunt. J Appl Physiol 1985; 59: 1790-1795.

22. Marchal F, Mazurek H, Habib M, Duvivier C, Derelle J,
Peslin R. Input respiratory impedance to estimate airway hyperreactivity in children: standard method versus head generator. Eur Respir J 1994; 7: 601-607.

23. Cauberghs M, Van de Woestijne KP. Changes of respiratory input impedance during breathing in humans. $J$ Appl Physiol 1992; 73: 2355-2362.

24. Baier H, Wanner A, Zarzecki S, Sackner MA. Relationships among glottis opening, respiratory flow, and upper airway resistance in humans. J Appl Physiol 1977; 43: 603-611.

25. Dubois AB. Resistance to breathing. In: Fenn WO, Rahn H, Eds. Handbook of Physiology - Respiration 1. Baltimore, William \& Wilkins, 1964; pp. 451-462.

26. Hantos Z, Adamicza A, Govaerts E, Daroczy. Mechanical impedances of lungs and chest wall in the cat. $J \mathrm{Appl}$ Physiol 1992; 73: 427-433.

27. Peslin R, Duvivier C. Partitioning of airway and respiratory tissue mechanical impedances by body plethysmography. J Appl Physiol 1998; 84: 553-561.

28. Tomalak W, Peslin R, Duvivier C. Respiratory tissue properties derived from flow transfer function in healthy humans. J Appl Physiol 1997; 82: 1098-1106.

29. Stocks J, Thomson A, Silverman M. The numerical analysis of pressure-flow curves in infancy. Pediatr Pulmonol 1985; 1: 19-26.

30. Beardsmore CS, Maayan C, Bar-Yishay E, Godfrey S. Flow-pressure looping during plethysmography in wheezy infants. Pediatr Pulmonol 1985; 1: 127-131.

31. Petak F, Hayden MJ, Hantos Z, Sly PD. Volume dependence of respiratory impedance in infants. Am J Respir Crit Care Med 1997; 156: 1172-1177.

32. Davidson RN, Greig CA, Hussain A, Saunders KB. Within-breath changes of airway calibre in patients with airflow obstruction by continuous measurement of impedance. Br J Dis Chest 1986; 80: 335-352.

33. Mitzner W, Blosser S, Yager D, Wagner E. Effect of bronchial smooth muscle contraction on lung compliance. J Appl Physiol 1992; 72: 158-167.

34. Brancatisano T, Collett PW, Engel LA. Respiratory movements of the vocal cords. J Appl Physiol 1983; 54: 1269 1276. 